\title{
Substantial difference between declared and real magnification in medical loupes
}

Klaus W Neuhaus*, Philippe Perrin and Adrian Lussi

*Correspondence: klaus.neuhaus@zmk.unibe.ch

Department of Preventive, Restorative and Pediatric Dentistry, School of Dental Medicine, University of Bern, Switzerland.

\begin{abstract}
Background: The use of magnification devices is widely recommended in surgical disciplines, but a validation of the respective optical aids, i.e., medical loupe systems, is lacking. The aim of this study was to objectively assess different medical loupe systems, including their declared magnification.

Methods: Six Galilean binocular loupes (Zeiss 2.5×, SurgiTel 2.5×, Merident DCI 2.5×, Orascoptic 2.8×, SwissLoupes $2.5 \times$ and $3.2 \times$ ) and three Keplerian binocular loupes (Zeiss 3.6×, SurgiTel 3.5 $\times$, Orascoptic 3.8 $\times$ ) were compared with regard to their optical characteristics. The working distance was $350 \mathrm{~mm}$ for all loupe systems except for Orascoptic (370 $\mathrm{mm})$. The magnification factor, field size and distortion were assessed and compared in an independent optical laboratory (NTB, Buchs, Switzerland).

$\underline{\text { Results: }}$ The following magnifications (declared/measured) and field sizes (in mm) were obtained: Zeiss $(2.5 \times / 2.7 \times ; 50)$, SurgiTel $(2.5 \times / 2.0 \times ; 80)$, Merident DCI $(2.5 \times / 2.6 \times ; 45)$, Orascoptic $(2.8 \times / 2.2 \times ; 85)$, SwissLoupes $(2.5 \times / 2.3 \times ; 50$ and $3.2 \times / 3.1 \times ; 30$

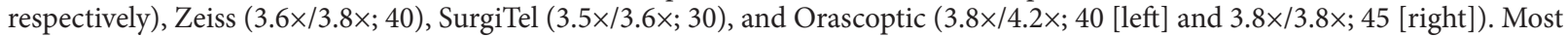
loupe systems showed a vertical and horizontal distortion less than $1^{\circ}$.

Conclusions: A great variance of magnification and field sizes could be measured in Galilean loupe systems. A lower real magnification than declared is most likely not a problem of manufacturing quality but based on commercial reasons: lower magnification correlates with bigger field size and wider focal range, both of which are good selling points. Keplerian loupe systems showed more consistency, although one loupe system differed between left and right ocular. A test for instant assessment of the effective magnification is desirable and proposed. Recommendations of medical Galilean loupes with certain declared magnification factors and studies based on them up to now must be regarded as biased with respect to the technical details reported here.
\end{abstract}

Keywords: Optical devices, visual aids, ocular vision, vision test

\section{Introduction}

The use of loupes has been recommended in several surgical medical disciplines. Obviously, medical loupes enhance vision and make it easier to identify small structures. A recent article recommended a $2.5 \times$ magnification for surgery with $8-0$ sutures in plastic eyelid surgery [1]. Furthermore, a $2.5 \times$ loupe magnification has also been recommended for emergency departments and found to be a valuable and inexpensive tool that aids foreign body identification and wound closure [2]. The identification of small structures might result in a benefit for the patient; a retrospective study with two cohorts of parathyroid gland removals with and without $2.5 \times$ loupe magnification found that the patients treated with loupes showed significantly less postoperative hypocalcaemia and a trend towards less damage to the recurrent laryngeal nerve [3]. In dental medicine, the use of magnification systems is generally recommended to support operative treatments [4], to support visual caries detection [5], and to enhance ergonomics [6]. Greater magnifications (i.e., operating microscope) have been proven to be useful in root canal treatments and are standard devices in endodontic specialist training [7].

Apart from professional purposes, it is known that the contrast sensitivity $[8,9]$ and accommodation $[10,11]$ decreases with increasing age due to presbyopia. Dentists $40 \mathrm{y}$ and older can compensate for their presbyopic deficiencies with a $2.5 \times$ magnification and achieve a visual acuity that is comparable to younger persons without visual deficiencies $[12,13]$.

For general dentistry purposes, Galilean loupes with $2.5 \times$ magnification are usually recommended [14]. This rather low magnification factor is a compromise between visual acuity and ergonomics, for which a relatively large field of vision and focal range are beneficial. For higher magnifications, Keplerian (synonym: prismatic) loupe systems are required. They offer greater magnifications due to their sophisticated optical system. However, there is a dilemma one is faced with between vision and ergonomics: the higher the magnification, the smaller the field of vision and range of focal distance. This dependence is implied by optical laws in physics. It could therefore be a selling point by manufacturers to proclaim a false (i.e., too high) magnification factor in order to achieve a larger working field and a wider range of focal distance than comparable loupes.

This study aimed at assessing objectively the optical properties of different medical loupe systems. The purpose was to verify if the indicated magnification factors were credible or not and if loupes with nominally equal optical properties can be regarded as equal. 
Neuhaus et al. Medical Instrumentation 2013,

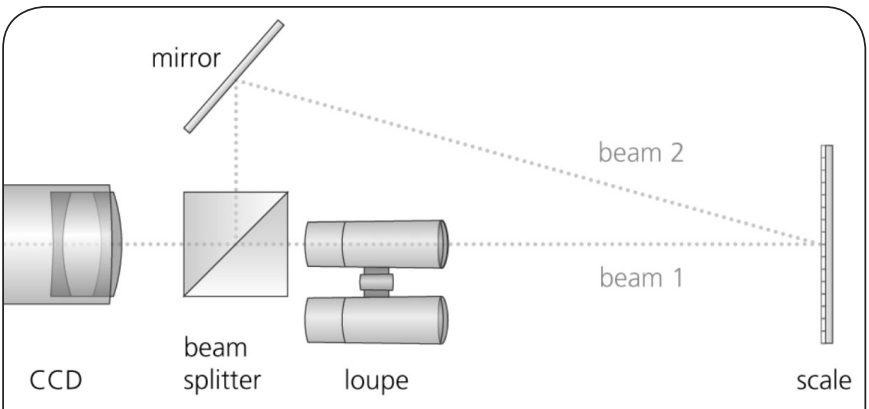

Figure 1. Optical bench assay for measurement of the real magnification factor of a medical loupe.

\section{Materials and methods}

A literature search was carried out in PubMed in May 2013, using the terms "magnifying loupes" and "magnification loupes". One hundred twenty-five different articles were obtained, out of which most were personal recommendations or explanatory articles with low external validity. Objective comparisons between different medical loupes have not been made so far. Due to an increasing number of available medical loupes on the market and due to costs of a laboratory setup, a selection had to be made. Widely distributed medical loupes from European and US American producers were chosen for further comparisons. We aimed at testing 10 different medical loupes and obtained consent to include 9 medical loupes in our study.

Thus, the optical properties of 6 Galilean binocular loupes (Zeiss 'EyeMag Smart' 2.5×, Zeiss, Jena, Germany; SurgiTel 2.5×, SurgiTel, Ann Arbor, MI, USA; Merident DCI $2.5 \times$, MeridentOptergo, Mölnycke, Sweden; Orascoptic 2.8x, Orascoptic, Middleton, WI, USA; SwissLoupes $2.5 \times$ and $3.2 \times$, SandyGrendel, Aarburg, Switzerland) and three Keplerian (prismatic) binocular loupes (Zeiss “EyeMag Pro" 3.6x, SurgiTel $3.5 \times$, Orascoptic 3.8X) were assessed and compared in an independent optical laboratory (NTB, Buchs, Switzerland). The working distance was $350 \mathrm{~mm}$ for all loupe systems except for Orascoptic (370 mm).

\section{Measurement of the magnification factor and field of vision}

The loupes were mounted in an optical bench assay with a beam splitting device in front of the tested loupe. A linear scale was fixed at a defined distance according to the manufacturer. A CCD camera captured a photograph both through a single ocular of each loupe system and through a mirror closely mounted to the dental loupe (Figure 1). In order to assess the real magnification factor, the two captured pictures were superimposed and the differences were calculated. The size of the field of vision could be read directly.

\section{Measurement of linear deviation}

Additionally, in the same assay, a planar scale replaced the linear scale, and a digital image was taken through each ocular. On each photograph, the linear deviation was measured using the software ImageJ (NIH, Bethesda, MD, USA).

\section{Results}

The magnification factors and field of views (in $\mathrm{mm}$ ) are listed in Table 1. None of the Galilean loupes showed the declared magnification factor of $2.5 \times$ (or $2.8 \times$ for Orascoptic), with a range from $2.0 \times$ to $2.7 \times$. The magnification factors of the Keplerian loupes were slightly above the declared values; one loupe system (Orascoptic) contained two lenses with different magnification factors. The vertical and horizontal distortion was smaller than $1^{\circ}$ for all loupe systems except one (SurgiTel: $1.91^{\circ}$ ). The field size of Galilean loupes $>2.5 \times$ was severely reduced (Table 1).

\section{Discussion}

This study is the first objective comparison of different medical loupe systems. Obvious and important discrepancies were found regarding the measured magnification among loupes with a nominally equal level of magnification. Galilean loupes with a nominal $2.5 \times$ magnification showed a range of $2.0 \times$ (SurgiTel) to $2.7 \times$ (Zeiss). This difference of $0.7 \times$ magnification makes up for a difference of $82 \%$ with respect to the optical information of a planar object. This finding is most probably not due to low production quality, but for concrete commercial reasons. Maximum optical depth and size of the visual field are attractive selling arguments with respect to dental ergonomics. The fact that the inverse relation between depth of field and magnification is an axiomatic physical law could result in a misleading (i.e., too high) declaration. No Galilean loupe system showed the magnification indicated by the manufacturer at the working distance.

The Keplerian loupe systems showed better consistency between nominal and measured magnification. However, in one sample (Orascoptic) the right and left lenses showed different magnification factors. As this manufacturer offers two loupe systems with the respective magnifications identified, it was assumed that this loupe was wrongly assembled during the manufacturing process.

Galilean loupes have a physical limit of the magnification factor, which can be extended with additional lenses. This increases along with distortions in the outer area of the field of view. By hiding the outer parts, most distortions can be masked. This is the reason for the small field size found in $3.2 x$ SwissLoupes, as an example for this type of loupe. Keplerian loupes are the instrument of choice for magnifications above 3.0x. They allow a free range of magnification without any optical impairment.

The magnification factor is crucial per se, but only one of the features used to characterize a medical loupe (as are weight, design, and price). The optical testing described in the present study is expensive, demanding, and time consuming, therefore an inexpensive and accessible device for ad hoc testing of the 
Neuhaus et al. Medical Instrumentation 2013,

Table 1. Comparison of different loupe systems.

\begin{tabular}{|c|c|c|c|c|c|c|c|c|c|c|c|c|c|c|c|c|c|c|}
\hline \multirow[b]{3}{*}{ working distance (mm) } & \multicolumn{12}{|c|}{ Galilei system } & \multicolumn{6}{|c|}{ Kepler system } \\
\hline & \multirow{2}{*}{\multicolumn{2}{|c|}{$\begin{array}{c}\text { merident DCI } \\
350\end{array}$}} & \multirow{2}{*}{\multicolumn{2}{|c|}{$\begin{array}{c}\text { Orascoptic } \\
370\end{array}$}} & \multirow{2}{*}{\multicolumn{2}{|c|}{$\begin{array}{c}\text { Surgitel } \\
350\end{array}$}} & \multicolumn{4}{|c|}{ Swissloupes } & \multirow{2}{*}{\multicolumn{2}{|c|}{$\begin{array}{c}\text { Zeiss } \\
350\end{array}$}} & \multirow{2}{*}{\multicolumn{2}{|c|}{$\begin{array}{c}\text { Orascoptic } \\
370\end{array}$}} & \multirow{2}{*}{\multicolumn{2}{|c|}{$\begin{array}{c}\text { Surgitel } \\
350\end{array}$}} & \multirow{2}{*}{\multicolumn{2}{|c|}{$\begin{array}{c}\text { Zeiss } \\
350\end{array}$}} \\
\hline & & & & & & & 35 & & & & & & & & & & & \\
\hline nominal magnification & \multicolumn{2}{|c|}{$2.5 x$} & \multicolumn{2}{|c|}{$2.8 \mathrm{x}$} & \multicolumn{2}{|c|}{$2.5 x$} & \multicolumn{2}{|c|}{$2.5 x$} & \multicolumn{2}{|c|}{$3.2 x$} & \multicolumn{2}{|c|}{$2.5 x$} & \multicolumn{2}{|c|}{$3.8 \mathrm{x}$} & \multicolumn{2}{|c|}{$3.5 x$} & \multicolumn{2}{|c|}{$3.5 x$} \\
\hline $\begin{array}{l}\text { measured magnification } \\
\text { (left/right) }\end{array}$ & $2.6 \mathrm{X}$ & $2.6 \mathrm{X}$ & $2.2 \mathrm{x}$ & $2.2 \mathrm{X}$ & $2.0 \mathrm{x}$ & $2.0 x$ & $2.3 x$ & $2.3 x$ & $3.1 \mathrm{x}$ & $3.1 \mathrm{x}$ & $2.7 \mathrm{X}$ & $2.7 X$ & $4.2 X^{a}$ & $3.8 \mathrm{X}^{\mathrm{a}}$ & $3.6 x$ & $3.6 \mathrm{X}$ & $3.8 \mathrm{x}$ & $3.8 \mathrm{x}$ \\
\hline field size $(\mathrm{mm})$ & 45 & 45 & 85 & 85 & 80 & 80 & 50 & 50 & 30 & 30 & 50 & 50 & 40 & 45 & 30 & 30 & 40 & 40 \\
\hline $\begin{array}{l}\text { vertical and horizontal } \\
\text { distortion }\end{array}$ & \multicolumn{2}{|c|}{$0.49^{\circ}-0.87^{\circ}$} & \multicolumn{2}{|c|}{$0.18^{\circ}-0.22^{\circ}$} & \multicolumn{2}{|c|}{$0^{\circ}-0.22^{\circ}$} & \multicolumn{2}{|c|}{$0^{\circ}-0.53^{\circ}$} & \multicolumn{2}{|c|}{$0^{\circ}-0.57^{\circ}$} & \multicolumn{2}{|c|}{$0^{\circ}-0.26^{\circ}$} & \multicolumn{2}{|c|}{$0^{\circ}-0.26^{\circ}$} & \multicolumn{2}{|c|}{$0.67^{\circ}-1.91^{\circ}$} & \multicolumn{2}{|c|}{$0^{\circ}-0.2^{\circ}$} \\
\hline \multicolumn{19}{|l|}{ photograph (left) } \\
\hline photograph (right) & & & & & & & & & & & & & & & & \# & & \\
\hline
\end{tabular}

* Obviously different loupes were mounted in the loupe system.

real magnification factor would be desirable. An example for such a fast and inexpensive test can be downloaded at [15].

\section{Conclusion}

A great variance in magnification and field size could be measured in Galilean loupe systems. The differences between their declared and effective magnification are in some cases important. A test for instant assessment of the effective magnification is desirable and proposed. Today, recommendations concerning medical Galilean loupes with certain declared magnification factors and studies based on them must be regarded as biased with regard to the technical properties assessed in the present study.

\section{Competing interests}

The authors declare they have no competing interests.

\section{Authors' contributions}

KWN, PP and AL conceived and designed the study. KWN drafted the manuscript. PP and AL critically appraised the manuscript. Final manuscript was read and approved by all the authors.

\section{Acknowledgement and funding}

We thank Anne Seeger, ZMK Bern, for creating the figure. This study was funded by the Department of Preventive, Restorative and Pediatric Dentistry, University of Bern.

\section{Publication history}

Received: 24-Apr-2013 Revised: 16-May-2013

Re-Revised: 17-May-2013 Accepted: 21-May-2013

Published: 24-May-2013

\section{References}

1. Choi $Y$ and Eo S: A new crease fixation technique for double eyelidplasty using mini-flaps derived from pretarsal levator tissues. Plast Reconstr Surg 2010, 126:1048-57. | Article | PubMed

2. Hart RG and Hall J: The value of loupe magnification: an underused tool in emergency medicine. Am J Emerg Med 2007, 25:704-7. | Article | PubMed
3. Pata G, Casella C, Mittempergher F, Cirillo L and Salerni B: Loupe magnification reduces postoperative hypocalcemia after total thyroidectomy. Am Surg 2010, 76:1345-50. | Article | PubMed

4. Baumann DF, Brauchli $L$ and van Waes $H$ : The influence of dental loupes on the quality of adhesive removal in orthodontic debonding. J Orofac Orthop 2011, 72:125-32. | Article | PubMed

5. Haak R, Wicht MJ, Hellmich M, Gossmann A and Noack MJ: The validity of proximal caries detection using magnifying visual aids. Caries Res 2002, 36:249-55. | Article | PubMed

6. Zitzmann NU, Chen MD and Zenhausern R: [Frequency and manifestations of back pain in the dental profession]. Schweiz Monatsschr Zahnmed 2008, 118:610-8. | PubMed

7. Taschieri S, Del Fabbro M, Weinstein T, Rosen E and Tsesis I: Magnification in modern endodontic practice. Refuat Hapeh Vehashinayim 2010, 27:18-22, 61. | PubMed

8. Sia DI, Martin S, Wittert G and Casson RJ: Age-related change in contrast sensitivity among Australian male adults: Florey Adult Male Ageing Study. Acta Ophthalmol 2012. | Article | PubMed

9. Nio YK, Jansonius NM, Fidler V, Geraghty E, Norrby S and Kooijman AC: Age-related changes of defocus-specific contrast sensitivity in healthy subjects. Ophthalmic Physiol Opt 2000, 20:323-34. | Article | PubMed

10. Pointer JS: The presbyopic add. I. Magnitude and distribution in a historical context. Ophthalmic Physiol Opt 1995, 15:235-40. | Article | PubMed

11. Pointer JS: Broken down by age and sex. The optical correction of presbyopia revisited. Ophthalmic Physiol Opt 1995, 15:439-43. | Article I PubMed

12. Eichenberger M, Perrin P, Neuhaus KW, Bringolf $U$ and Lussi A: Influence of loupes and age on the near visual acuity of practicing dentists. $J$ Biomed Opt 2011, 16:035003. | Article | PubMed

13. Eichenberger $M$, Perrin $P$, Neuhaus KW, Bringolf $U$ and Lussi A: Visual acuity of dentists under simulated clinical conditions. Clin Oral Investig 2013, 17:725-9. | Article | PubMed Abstract | PubMed Full Text

14. Weathers AK: Access to success: taking a closer look at magnification. Dent Today 2005. I Website

15. Ulvio K: Testing true magnification. 2013. | Website

\section{Citation:}

Neuhaus KW, Perrin P and Lussi A: Substantial difference between declared and real magnification in medical loupes. Medical Instrumentation 2013, 1:2. http://dx.doi.org/10.7243/2052-6962-1-2 